Research Article

\title{
A Study on Triaxial Unloading Test of Columnar-Jointed-Rock-Mass-Like Material with AW Velocity Analysis
}

\author{
Jianrong Xu, ${ }^{1}$ Hao Li, ${ }^{2,3}$ Qingxiang Meng, ${ }^{2,3}$ Weiya Xu $\mathbb{D}^{2,3}$ Mingjie He, ${ }^{1}$ and Jiahui Yang ${ }^{2,3}$ \\ ${ }^{1}$ Powerhouse Design Department, Huadong Engineering Corporation Limited, Hangzhou, China \\ ${ }^{2}$ Research Institute of Geotechnical Engineering, Hohai University, Nanjing, China \\ ${ }^{3}$ Key Laboratory of Ministry of Education for Geomechanics and Embankment Engineering, Hohai University, Nanjing, China
}

Correspondence should be addressed to Weiya Xu; wyxuhhu@163.com

Received 15 October 2020; Revised 8 November 2020; Accepted 12 December 2020; Published 24 December 2020

Academic Editor: Chun Zhu

Copyright (c) 2020 Jianrong Xu et al. This is an open access article distributed under the Creative Commons Attribution License, which permits unrestricted use, distribution, and reproduction in any medium, provided the original work is properly cited.

To study the strength, deformation, and failure patterns of columnar-jointed-rock-mass (CJRM) under unloading conditions, triaxial unloading tests using the CJRM-like material samples are carried out, and acoustic wave (AW) velocities are simultaneously recorded. Based on stress-strain curves and AW velocities under different initial confining pressures and unloading rates, the stress-strain characteristics, strength, and deformation parameters, failure modes, and variation of the AW velocity are analyzed. Test results show that the CJRM may exhibit intense volume expansion during the unloading process. With the increase of the unloading and its rate, the volume expansion becomes more serious and the failure mode becomes more complicated. By reducing the unloading (rate), a phenomenon of unloading relaxation is observed and the quality of CJRM is significantly improved. The AW velocity of CJRM shows a strong correlation with the volume strain, which verifies the effectiveness of applying AW velocity for assessing the rock quality. It is hoped that the research results may provide a reference for the construction and operation of the Baihetan Hydropower Project.

\section{Introduction}

The Baihetan Hydropower Station is located at the lower reaches of the Jinsha River. The barrage is a double-curvature arch dam with the height of $289 \mathrm{~m}$. The Baihetan arch dam foundation is mainly composed of columnar-jointed basalt, which contains abundant joint surfaces and microcracks thus having indispensable effects on the foundation stability. The physical and mechanical property of columnarjointed basalt were conducted by many scholars [1-8]. However, the construction of hydropower station usually involves excavation procedures that could cause intense unloading relaxation phenomenon in columnar-jointed basalt.

In order to understand the unloading relaxation characteristics of the columnar-jointed basalt in Baihetan dam area, it is necessary to explore its unloading mechanism with more details. Laboratory experimental study is implemented to study unloading mechanics of jointed rock [9-15]. Also, in-situ test is another important method for the relaxation characteristics $[16,17]$. The results indicate that the unloading relaxation depth of columnar-jointed basalt is influenced by the crustal stress, the rock mass quality, and the inclined shear zone.

In this study, triaxial unloading tests using columnarjointed-rock-mass- (CJRM-) like material samples are carried out to further study the unloading relaxation characteristics of columnar-jointed basalt of Baihetan arch dam foundation. The acoustic wave (AW) velocities are simultaneously recorded. The stress-strain curves, variation of $\mathrm{AW}$ velocities, and failure modes are obtained and analyzed. The research results will help to explore the unloading relaxation characteristics and deformation patterns of CJRM, thus having application value. 


\section{Experiment Scheme}

2.1. Preparation of CJRM-Like Material Samples. The studies on heterogeneous geomaterials indicate that the microstructure plays an important role in the mechanical properties [8, 18-22]. Given that the joint dips of columnarjointed basalt in the Baihetan area are basically round $75^{\circ}$, the CJRM-like material samples used in the triaxial unloading tests in this paper are all designed with a joint dip of $75^{\circ}$. According to the testing standards of the International Society for Rock Mechanics (ISRM), the sample diameter and height are, respectively, $50 \mathrm{~mm}$ and $100 \mathrm{~mm}$. The cement mortar with the properties in Table 1 is used to make the CJRM-like material samples that share the same structure and mechanical properties with the columnarjointed basalts. Production procedure of the CJRM-like material samples are as follows.

(1) Produce single column by mold pouring method. The mold is made of acrylic material, and regular hexagonal prism grooves with the length of $5 \mathrm{~mm}$ are arranged within the molds. To facilitate the demolding process, Vaseline is smeared on the inner surface of molds. The molds are assembled and fixed using high-strength rubber bands.

(2) Mix high-strength Portland cement, fine sands (particle size $<1 \mathrm{~mm}$ ), Polycarboxylate Superplasticizer, and water into the cement mortar by mass ratio of $1: 0.5: 0.4: 0.002$. A syringe is used to inject the cement mortar into molds from the bottom up, allowing cement mortar to fully fill the hexagonal space and avoiding air bubbles.

(3) Store the molds with temperature of $20 \pm 2^{\circ} \mathrm{C}$ and relative humidity of $95 \%$ for 24 hours. Once the columns are strong enough, open the mold and take out the columns. Choose standard columns with diagonal of $10 \mathrm{~mm}$ and cure them with constant temperature and humidity.

(4) Bond the columns neatly and tightly into a block using white cement (shown in Figure 1), and put the blocks into curing room. Then, cut the cured block at the dip of $75^{\circ}$ to form standard cylindrical samples. At last, the measured physical and geometric parameters of the test samples are shown in Table 2.

2.2. Experiment Steps. The rock mass is naturally under complicated spatial stress states, and it is usually difficult to judge whether it is under loading or unloading state. In contrast, during the process of triaxial unloading test, the loading or unloading state can be artificially controlled by increasing or decreasing the axial and confining pressures. Figure 2 shows the stress path control methods in 4 test types. Path 1 is the conventional triaxial loading test, path 2 is the triaxial unloading test, path 3 is the triaxial unloading test under constant axial pressure, and path 4 is the triaxial unloading test under decreased confining pressure. The triaxial loading test is firstly
TABle 1: Physical and mechanical properties of the cement mortar.

\begin{tabular}{lc}
\hline Property & Value \\
\hline Density $\left(\mathrm{g} / \mathrm{cm}^{3}\right)$ & 2.19 \\
Elastic modulus $(\mathrm{GPa})$ & 16.03 \\
Poisson's ratio & 0.24 \\
Cohesion $(\mathrm{MPa})$ & 14.35 \\
Friction angle $\left(^{\circ}\right)$ & 38.7 \\
\hline
\end{tabular}

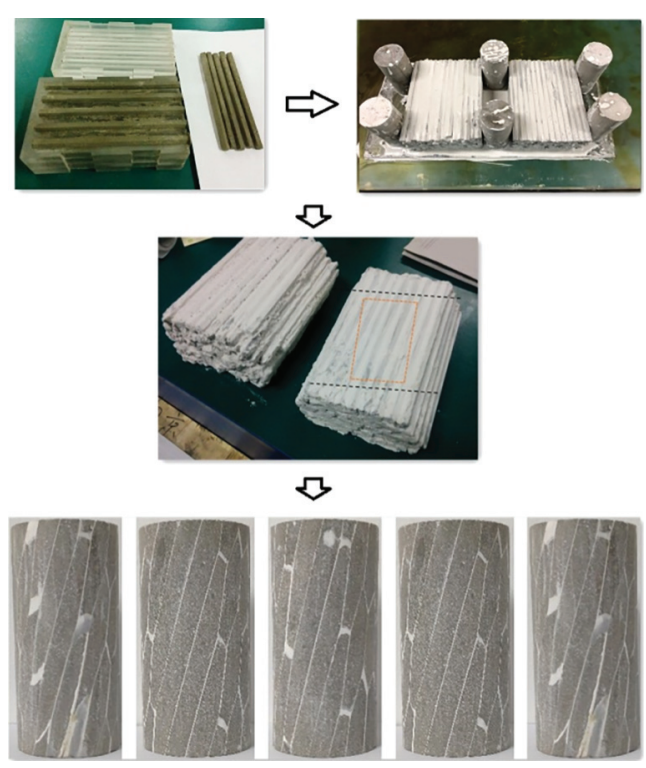

FIgure 1: Production procedure of CJRM-like material samples.

TABLe 2: Physical and geometric parameters of CJRM-like material samples.

\begin{tabular}{lccc}
\hline No. & Diameter $(\mathrm{mm})$ & Height $(\mathrm{mm})$ & Mass $(\mathrm{g})$ \\
\hline BHT-75-1 & 49.97 & 99.78 & 412.62 \\
BHT-75-2 & 50.18 & 100.25 & 416.01 \\
BHT-75-3 & 50.17 & 99.69 & 413.65 \\
BHT-75-4 & 50.17 & 100.39 & 418.23 \\
BHT-75-5 & 50.10 & 100.43 & 413.95 \\
\hline
\end{tabular}

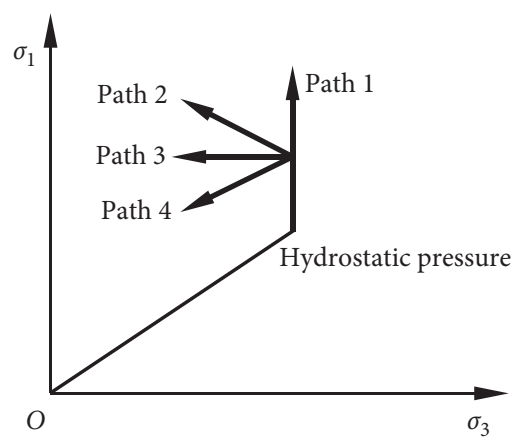

FIgURE 2: Stress paths of four triaxial unloading test methods.

employed to get the peak stress and the unloading point is chosen as $70 \% \sim 80 \%$ of the peak stress based on previous studies $[23,24]$. This paper adopts the triaxial unloading test under constant axial pressure (path 3), and detailed test plans are shown in Table 3. 
TABLE 3: Test plan of CJRM-like material samples.

\begin{tabular}{lcccccc}
\hline No. & $\begin{array}{c}\text { Initial confining } \\
\text { pressure }(\mathrm{MPa})\end{array}$ & $\begin{array}{c}\text { Loading rate } \\
(\mathrm{mm} / \mathrm{min})\end{array}$ & $\begin{array}{c}\text { Unloading rate } \\
(\mathrm{MPa} / \mathrm{min})\end{array}$ & $\begin{array}{c}\text { Peak strength } \\
(\mathrm{MPa})\end{array}$ & $\begin{array}{c}\text { Predetermined deviatoric } \\
\text { stress }(\mathrm{MPa})\end{array}$ & $\begin{array}{c}\text { Unloading } \\
\text { ratio }\end{array}$ \\
\hline BHT-75-1 & 6.0 & & 0.5 & 52.76 & 36.53 & 0.69 \\
BHT-75-2 & 6.0 & & 1.0 & 52.76 & 37.69 & 0.71 \\
BHT-75-3 & 6.0 & 0.02 & 2.0 & 52.76 & 38.95 & 0.74 \\
BHT-75-4 & 4.0 & & 0.5 & 47.91 & 34.17 & 0.71 \\
BHT-75-5 & 8.0 & & 0.5 & 52.76 & 41.97 \\
\hline
\end{tabular}

The triaxial unloading test is carried out on an automatic triaxial servo platform (Figure 3). Steps are as follows: apply predetermined confining pressures of $4 \mathrm{MPa}, 6 \mathrm{MPa}$, and $8 \mathrm{MPa}$, wait until the confining pressure is stable, and apply axial pressure in a strain-controlled manner to obtain the full stress-strain curve with postpeak phase. Specific test operation procedures are as follows:

(1) Measure physical and geometric parameters of the test samples. Place upper cushion block, rock sample, and lower block on the same central axis, and install axial strain sensors and circumferential strain rings. Put them into pressure chamber of the automatic triaxial servo instrument and make sure it is on the pressure axis.

(2) Apply confining pressure at a loading rate of $7.5 \mathrm{MPa} / \mathrm{min}$ until it reaches predetermined value. After the stability of confining pressure, add the axial pressure to the predetermined value (about $70 \%$ of the peak strength during triaxial compression test). When the axis pressure remains stable, unload the confining pressure at a rate of $0.2 \mathrm{MPa} / \mathrm{min}$ until the sample is broken. Record the stress-strain curve during the unloading process.

(3) Remove the rock sample, record the failure mode, and collect data.

\section{Unloading Test Results with Different Initial Confining Pressures}

3.1. Stress-Strain Curves. The stress-strain curves of CJRMlike material samples under initial confining pressure of 4.0 MPa, 6.0 MPa, and 8.0 MPa are, respectively, shown in Figure 4. Apparently, these stress-strain curves can be divided into two phases. In phase I, the confining pressure remains constant while the deviatoric stress increases. The stress-strain curve contains initial nonlinear compaction stage and liner elastic stage, which is similar to triaxial compression tests. Phase II is the unloading process. The deviatoric stress remains constant while the confining pressure decreases. As a result, both the axial and the circumferential deformations increase significantly, and the dilatancy failure along the joint plane gradually develops.

By comparing the unloading stress-strain curves of CJRM-like material samples under different initial confining pressures, it can be found that reducing the confining pressure has a remarkable influence on both the axial and circumferential deformations: with decrease of the confining

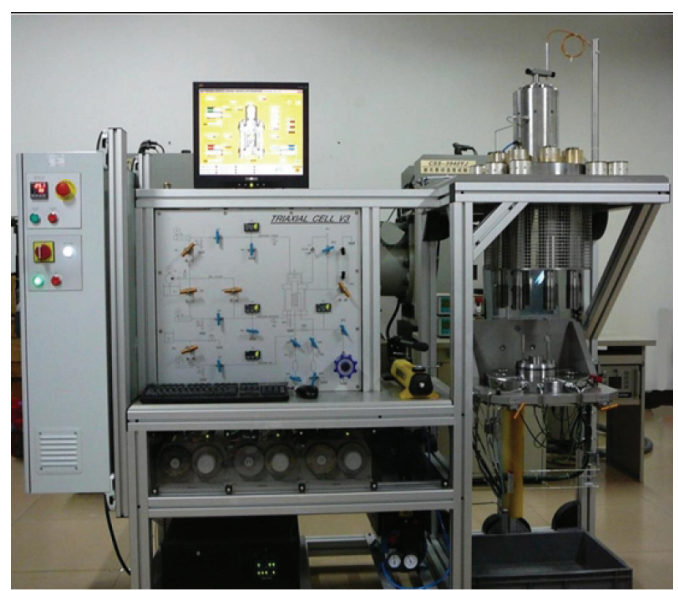

Figure 3: Automatic triaxial servo platform.

pressure, axial deformation increases and the circumferential deformation increases negatively.

3.2. Deformation Modulus. In triaxial unloading tests, deformation parameters of CJRM-like material samples can be obtained by the following equation $[25,26]$ :

$$
E=\frac{\left(\sigma_{1}-2 \mu \sigma_{2}\right)}{\varepsilon_{1}} .
$$

Figure 5 shows the relationship curves between the deformation modulus and confining pressure under different initial confining pressures (4.0 MPa, 6.0 MPa, and $8.0 \mathrm{MPa}$ ) during the unloading process. As can be seen, the deformation modulus of test samples is among 1-7 GPa and it shows nonlinear reduction with decrease of the confining pressure. In the early stage of the unloading process, the decrease rate of deformation modulus remains relatively low. However, as the confining pressure decreases further, the unloading amount increases and the deformation modulus reduces rapidly till failure of the sample. It can be found that test samples with different initial confining pressures have different failure confining pressures: failure confining pressures of CJRM-like material samples corresponding to initial confining pressures of $4.0 \mathrm{MPa}, 6.0 \mathrm{MPa}$, and $8.0 \mathrm{MPa}$ are, respectively, $1.41 \mathrm{MPa}, 3.64 \mathrm{MPa}$, and $6.53 \mathrm{MPa}$.

3.3. Failure Modes. Under different initial confining pressures, the main failure mode of CJRM-like material sample with joint dip of $75^{\circ}$ is the splitting failure along 


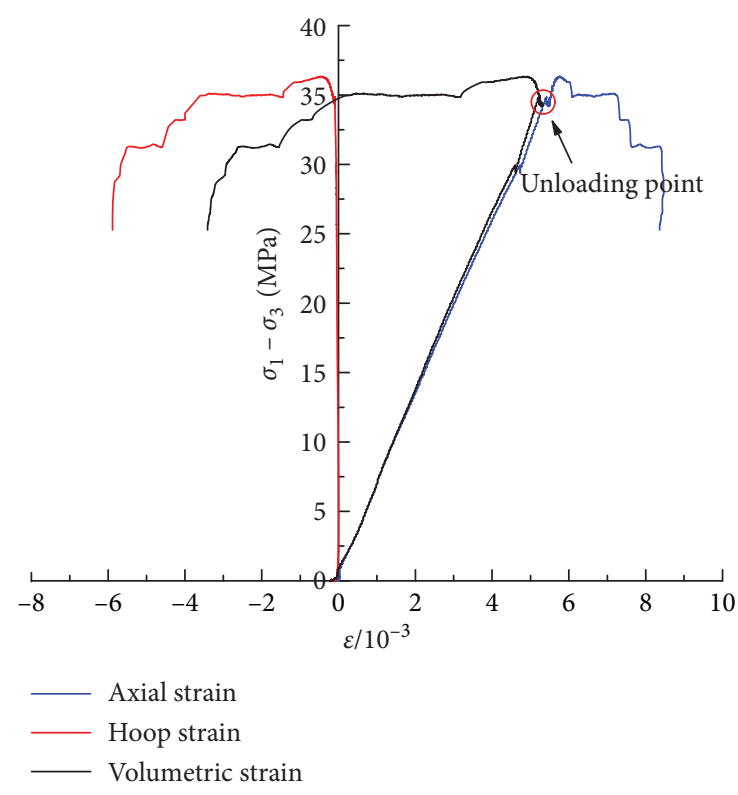

(a)

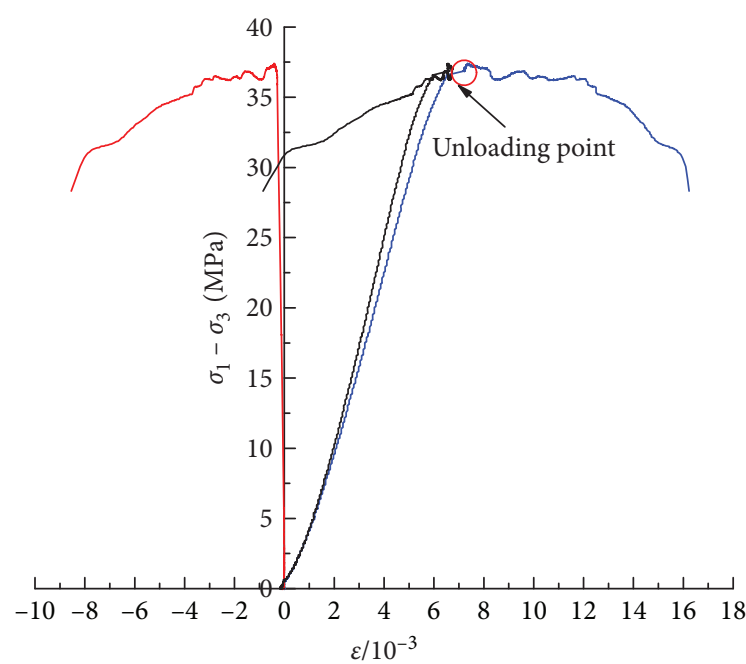

- Axial strain

Volumetric strain

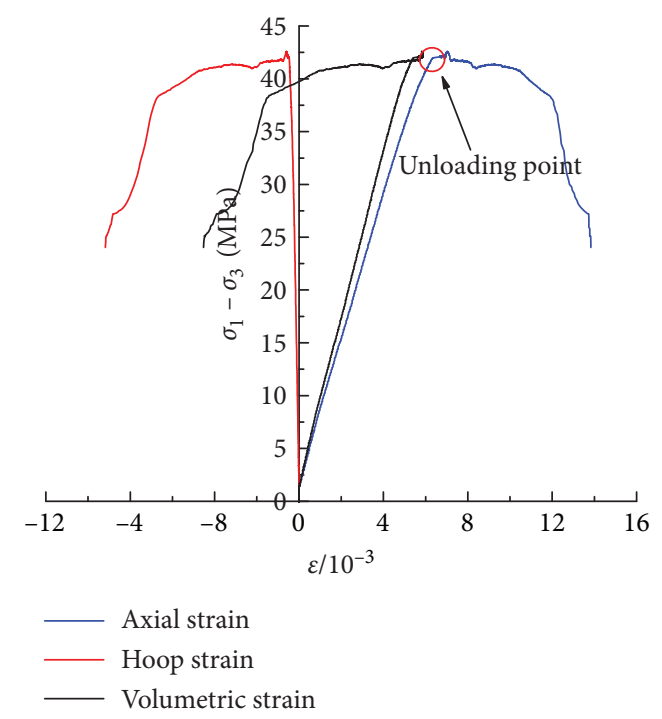

(b)

(c)

FiguRE 4: Stress-strain curves under different initial confining pressures. (a) $4.0 \mathrm{MPa}$, (b) $6.0 \mathrm{MPa}$, and (c) $8.0 \mathrm{MPa}$.

the joint plane (shown in Figure 6). When the initial confining pressure is $4.0 \mathrm{MPa}$ or $6.0 \mathrm{MPa}$, the test sample is forced to split along joint plane by axial pressure, and the columns finally collapse. When the initial confining pressure is $8.0 \mathrm{MPa}$, the test sample shows slipping failure along the joint plane. The outer columns spall and break due to shear stress. Meanwhile, transverse cracks causing columns to break are formed because neighboring columns slip at different rates and they squeeze each other laterally. The shear slip of columns is proved by their relative displacements. The occurrence of cracks on the surface of column indicates that, during the unloading process, the decrease of confining pressure causes tensile cracks that will be sheared and slip. This finally leads to the tensile-shear combined failure mode of the test sample. As a conclusion, with increase of the initial confining pressure (or unloading amount) during the triaxial unloading test, the collapse of CJRM-like material sample becomes more serious and the failure mode becomes more complicated.

\section{Unloading Test Results with Different Unloading Rates}

4.1. Stress-Strain Curves. The stress-strain curves of CJRMlike material samples under initial confining pressure of $6.0 \mathrm{MPa}$ and unloading rates of $0.5 \mathrm{MPa} / \mathrm{min}, 1.0 \mathrm{MPa} / \mathrm{min}$, and $2.0 \mathrm{MPa} / \mathrm{min}$ are shown in Figure 7 . In general, the stress-strain curves at different unloading rates have similar pattern with two phases. In phase I, the confining pressure 


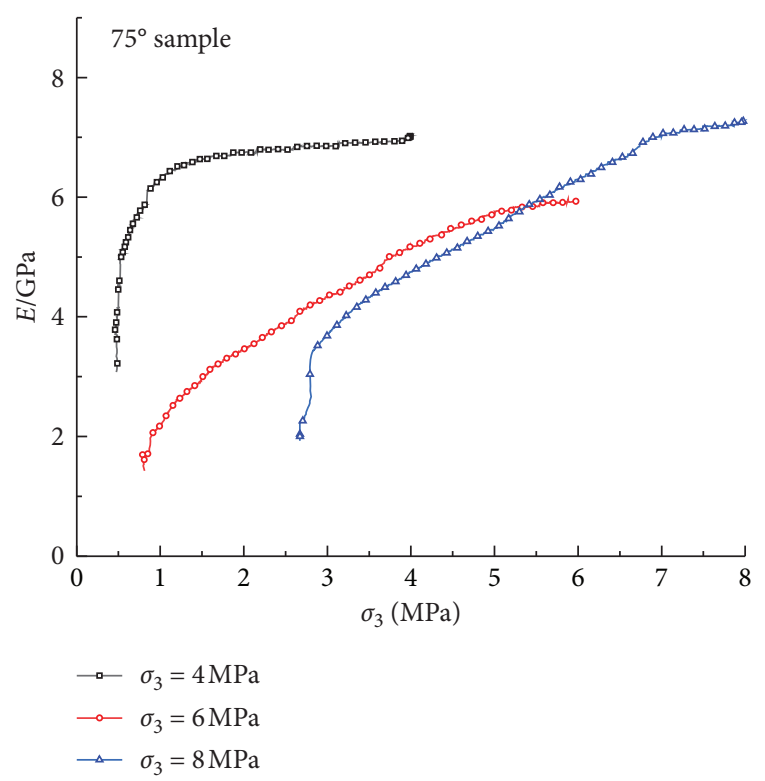

Figure 5: Relation curves of deformation modulus and confining pressure.

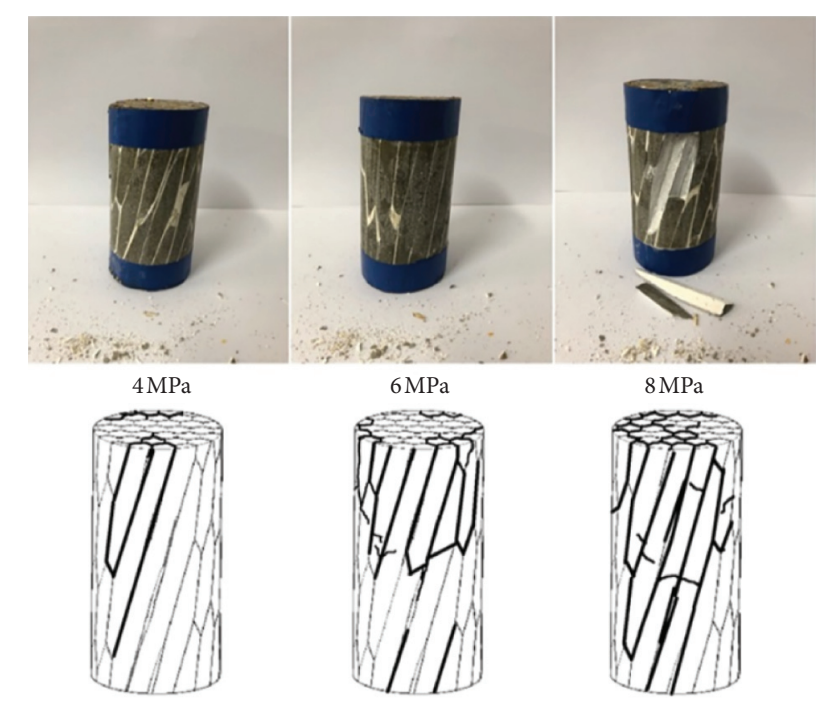

FIgURE 6: Failure modes under different initial confining pressures.

remains constant while the deviatoric stress increases; in phase II, the deviatoric stress remains constant while the confining pressure reduces at a constant rate. With unloading of the confining pressure, both the axial and the circumferential deformations increase rapidly and the volume dilatancy occurs.

By comparing and analyzing the stress-strain curves of rock samples under constant initial pressure with different unloading rates $(0.5 \mathrm{MPa} / \mathrm{min}, 1.0 \mathrm{MPa} / \mathrm{min}$, and $2.0 \mathrm{MPa} /$ $\mathrm{min}$ ), it can be found that the unloading process has significant effect on both axial and circumferential deformations. Specifically, with unloading of the confining pressure, the axial deformation increases and the circumferential deformation increases negatively. It is worth noting that when the unloading rate is $0.5 \mathrm{MPa} / \mathrm{min}$, the stress-strain curve in unloading stage fluctuates significantly. However, when the unloading rate increases to $2.0 \mathrm{MPa} / \mathrm{min}$, the stress-strain curve becomes smoother. Such a phenomenon indicates that when the unloading rate is relatively low, the failure of rock sample is a process of damage accumulation with evolution of partial failure to overall failure; the higher the unloading rate, the steeper the stress-strain curve. The increase of unloading rate accelerates the failure of CJRMlike material samples.

4.2. Deformation Modulus. Figure 8 shows the relationship curves between deformation modulus and confining pressure of rock sample at different unloading rates $(0.5 \mathrm{MPa} /$ $\min , 1.0 \mathrm{MPa} / \mathrm{min}$, and $2.0 \mathrm{MPa} / \mathrm{min})$. In general, the deformation modulus of test samples with joint dip of $70^{\circ}$ is among $1.49 \sim 6.44 \mathrm{GPa}$, and it increases with the unloading rate $(5.93 \mathrm{GPa}$ to $0.5 \mathrm{MPa} / \mathrm{min} ; 6.18 \mathrm{GPa}$ to $1.0 \mathrm{MPa} / \mathrm{min}$; 6.44 $\mathrm{GPa}$ to $2.0 \mathrm{MPa} / \mathrm{min}$ ). Deformation modulus also shows a nonlinear reduction with decrease of the confining pressure. In the early stage of the unloading process, the decrease rate of the deformation modulus remains relatively low. However, as the confining pressure decreases further, the unloading amount increases and the deformation modulus decreases rapidly till failure of the rock sample. It can be found that rock samples with different unloading rates have different failure confining pressures: failure confining pressures of CJRM-like material samples corresponding to unloading rates of $0.5 \mathrm{MPa} / \mathrm{min}, 1.0 \mathrm{MPa} / \mathrm{min}$, and $2.0 \mathrm{MPa} /$ min are, respectively, 3.64 MPa, 3.88 $\mathrm{MPa}$, and $4.24 \mathrm{MPa}$.

4.3. Failure Modes. At different unloading rates, the main failure mode of CJRM-like material samples with joint dip of $75^{\circ}$ is the splitting failure along the column axis (shown in Figure 8). With unloading rate at $0.5 \mathrm{MPa} / \mathrm{min}$ or $1.0 \mathrm{MPa} /$ min, the rock sample was forced to split along the joint plane by axial pressure, and the columns finally collapsed. Meanwhile, transverse cracks causing columns to break are formed because neighboring columns slip at different rates and they squeeze each other laterally. The shear slipping of columns is proved by their relative displacements. The occurrence of cracks on the surface of columns indicates that, during the unloading process, decrease of confining pressure causes tensile cracks, and tensile cracks are sheared and slip along the crack surfaces, which finally leads to the tensileshear combined failure mode of rock sample. When the unloading rate is $2.0 \mathrm{MPa} / \mathrm{min}$, the failure mode is combined failure of joint planes and columns, so strength of rock mass is now controlled by both cement mortar columns and weak surfaces. The increase of unloading rate accelerates the failure of rock samples. Slipping failure along joint plane occurs first, but the slipping rate is lower than the failure rate. Therefore, when the confining pressure is released quickly, stress on columns can reach its compression resistance. That is mainly why combined failure of joint planes and columns occurs at the unloading rate of $2.0 \mathrm{MPa} / \mathrm{min}$.

In addition, the failure mode of rock samples shows a drastic expansion phenomenon in transverse direction. As is shown in Figure 9, under the same initial confining pressure 


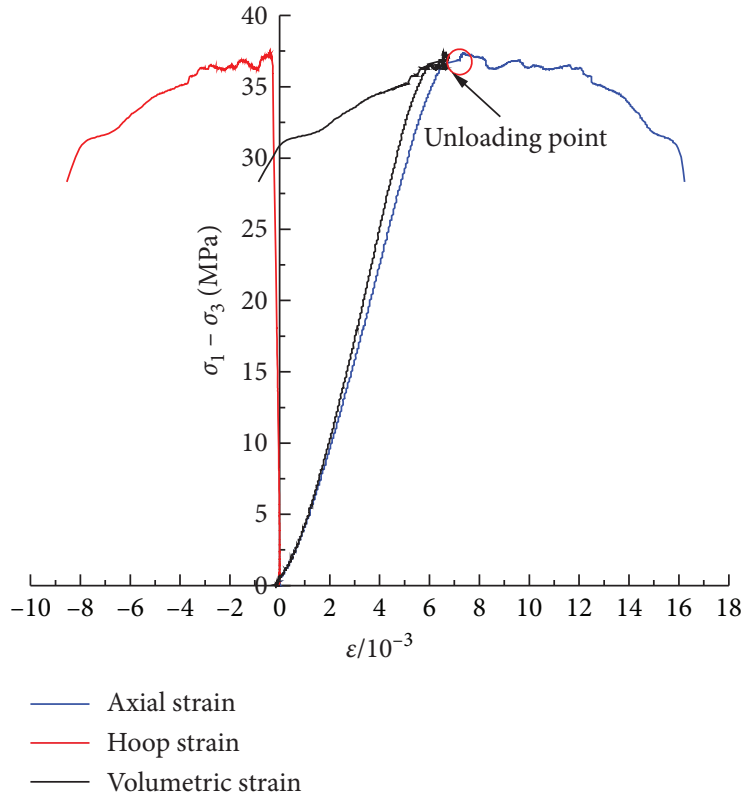

(a)

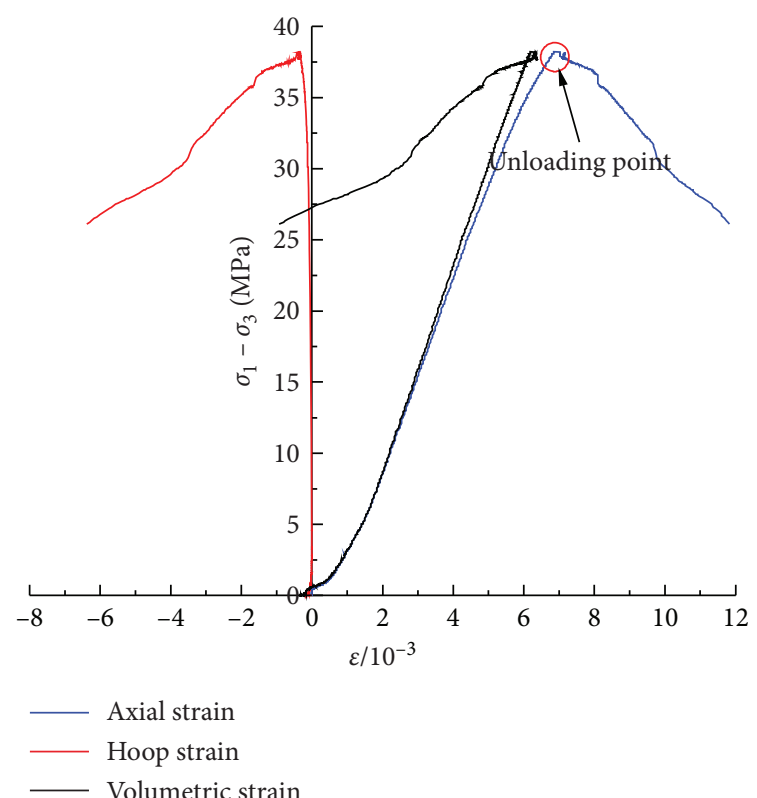

(b)

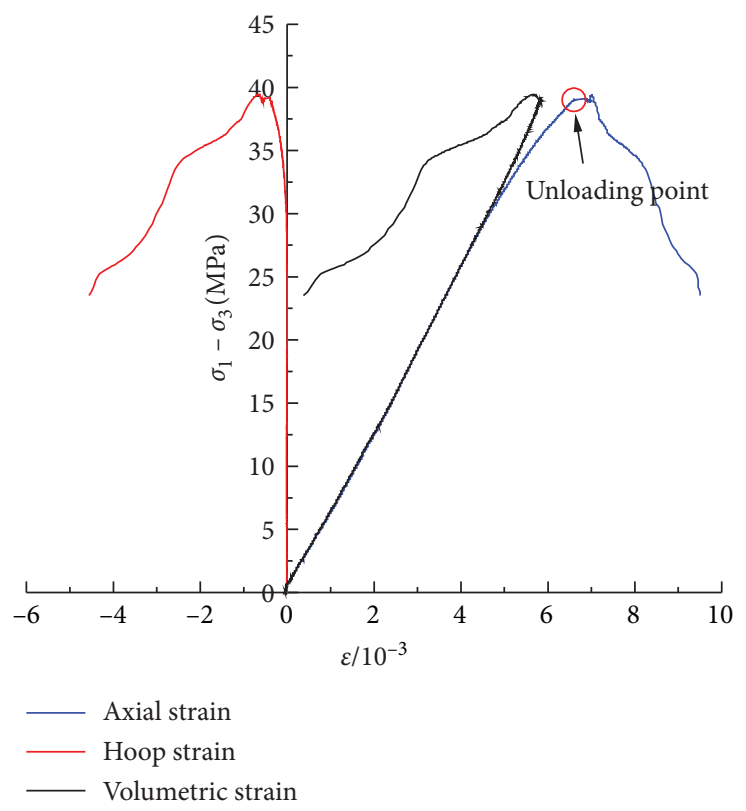

(c)

Figure 7: Stress-strain curves at different unloading rates. (a) $0.5 \mathrm{MPa} / \mathrm{min}$, (b) $1.0 \mathrm{MPa} / \mathrm{min}$, and (c) $2.0 \mathrm{MPa} / \mathrm{min}$.

(unloading amount), the volume dilatancy of rock sample becomes more obvious with the increase of the unloading rate, and the failure mode of CJRM-like material samples is also more complicated.

\section{Wave Speed Characteristic Analysis}

5.1. Principle of Acoustic Wave (AW) Test. The AW test adopts the transmit-receive method. As shown in Figure 10, AW is emitted from the bottom of the test sample by ultrasonic transmitter and received at the top of the test sample by acoustic receiving transducer. While conducting triaxial unloading test, audiogram of AW propagating in the rock sample is simultaneously recorded. After data processing, relation between AW velocity and rock mass integrity is established.

The AW velocity is calculated as follows:

$$
\begin{aligned}
& \Delta t=t_{1}-t_{2}, \\
& v_{p}=\frac{L}{\Delta t},
\end{aligned}
$$

where $t_{1}$ is the time of receiving the first AW crest of excited signal, $t_{2}$ is the time of receiving the first AW crest of excited signal when the transmitter and receiver are in direct 


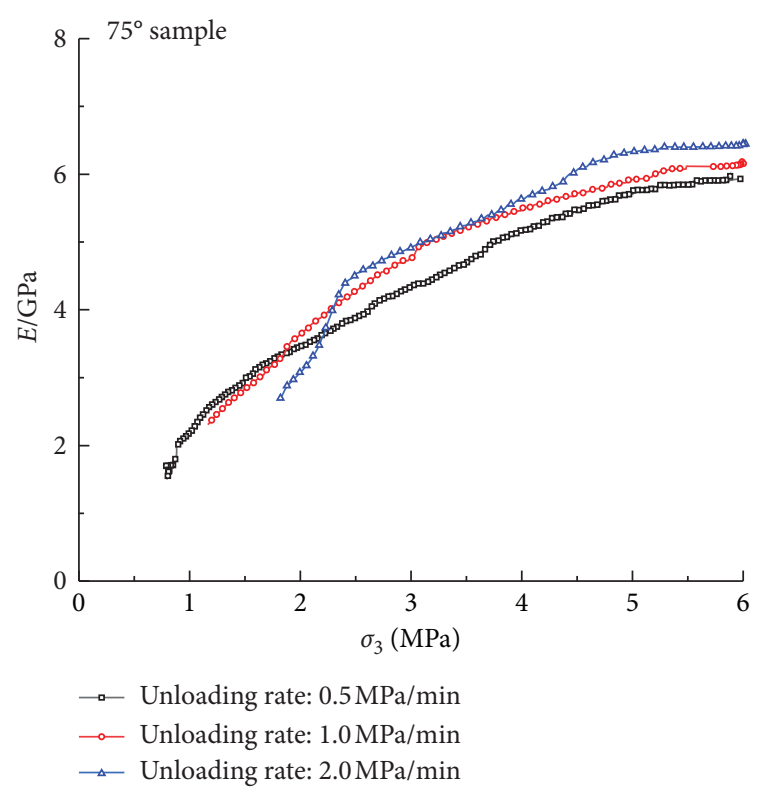

FIGURE 8: Relation curves of deformation modulus and confining pressure.

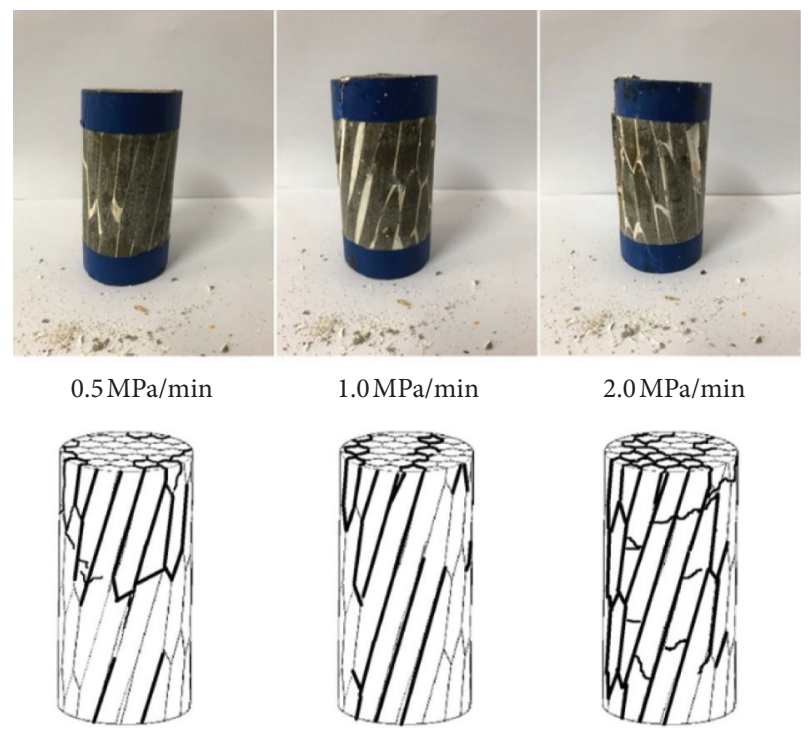

Figure 9: Failure modes at different unloading rates.

contact, $\Delta t$ is the time difference between $t_{1}$ and $t_{2}, L$ is the distance between transmitter and receiver (the height of the rock sample), and $v_{p}$ is the AW velocity. During the unloading process, the variation of strain state changes the velocity of AW propagating in rock samples. The AW form at different moments is recorded and processed to obtain AW velocity during the unloading process.

To improve the accuracy of test data, coupling agent is smeared between rock sample and transmitter, rock sample and receiver. Figure 11 shows that the waveforms recorded at different moments of unloading process are different. The wave amplitude as well as the receiving time of wave with corresponding phase changes. In Baihetan foundation area, abundant AW tests of long-term observation holes were

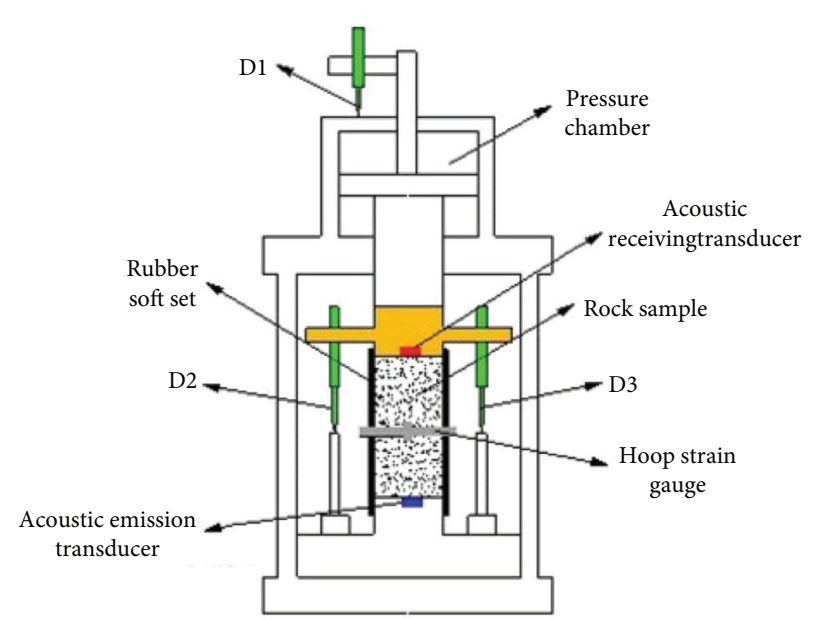

FIGURE 10: Schematic diagram of ultrasonic transmit-receive device [27].

carried out. To obtain corresponding results with project sites and make comparison, this paper studied the wave velocity characteristics of the CJRM-like material samples during triaxial unloading tests.

5.2. AW Velocity under Different Initial Confining Pressures. The initial confining pressures of the tests are $4.0 \mathrm{MPa}$, 6.0 MPa, and 8.0 MPa, and the unloading rate of the confining pressure is uniformly at $0.5 \mathrm{MPa} / \mathrm{min}$. Variations of AW velocity during the test are recorded as shown in Figure 12. Velocity variations of AW under different initial confining pressures (unloading amounts) generally have the same trend: increase slightly in the axial compaction stage and drop rapidly during the unloading process after the unloading point. However, values of initial wave velocities and failure wave velocities under different initial confining pressures are different: under confining pressure of $4.0 \mathrm{MPa}$, the initial wave velocity is $2825 \mathrm{~m} / \mathrm{s}$ and the failure wave velocity is $2699 \mathrm{~m} / \mathrm{s}$; under confining pressure of $6.0 \mathrm{MPa}$, the initial wave velocity is $3111 \mathrm{~m} / \mathrm{s}$ and the failure wave velocity is $2632 \mathrm{~m} / \mathrm{s}$; under confining pressure of $8.0 \mathrm{MPa}$, the initial wave velocity is $3151 \mathrm{~m} / \mathrm{s}$ and the failure wave velocity is $2580 \mathrm{~m} / \mathrm{s}$. Thus, there is obviously a strong relation between AW velocity characteristic and initial confining pressure (unloading amount).

Relation curves of AW velocity and initial confining pressure are shown in Figure 13. With the increase of initial confining pressure, both initial wave velocity and peak wave velocity increase while the failure wave velocity decreases. Under all initial confining pressures, failure wave velocity is the lowest, and peak wave velocity is a little bit higher than the initial wave velocity. Additionally, the initial wave velocity curve and the failure wave velocity curve form a rightward trumpet shape, indicating that the velocity difference is positively related with unloading amount. The larger the initial confining pressure is, the more the wave velocity drops after the failure of CJRM-like material samples. 


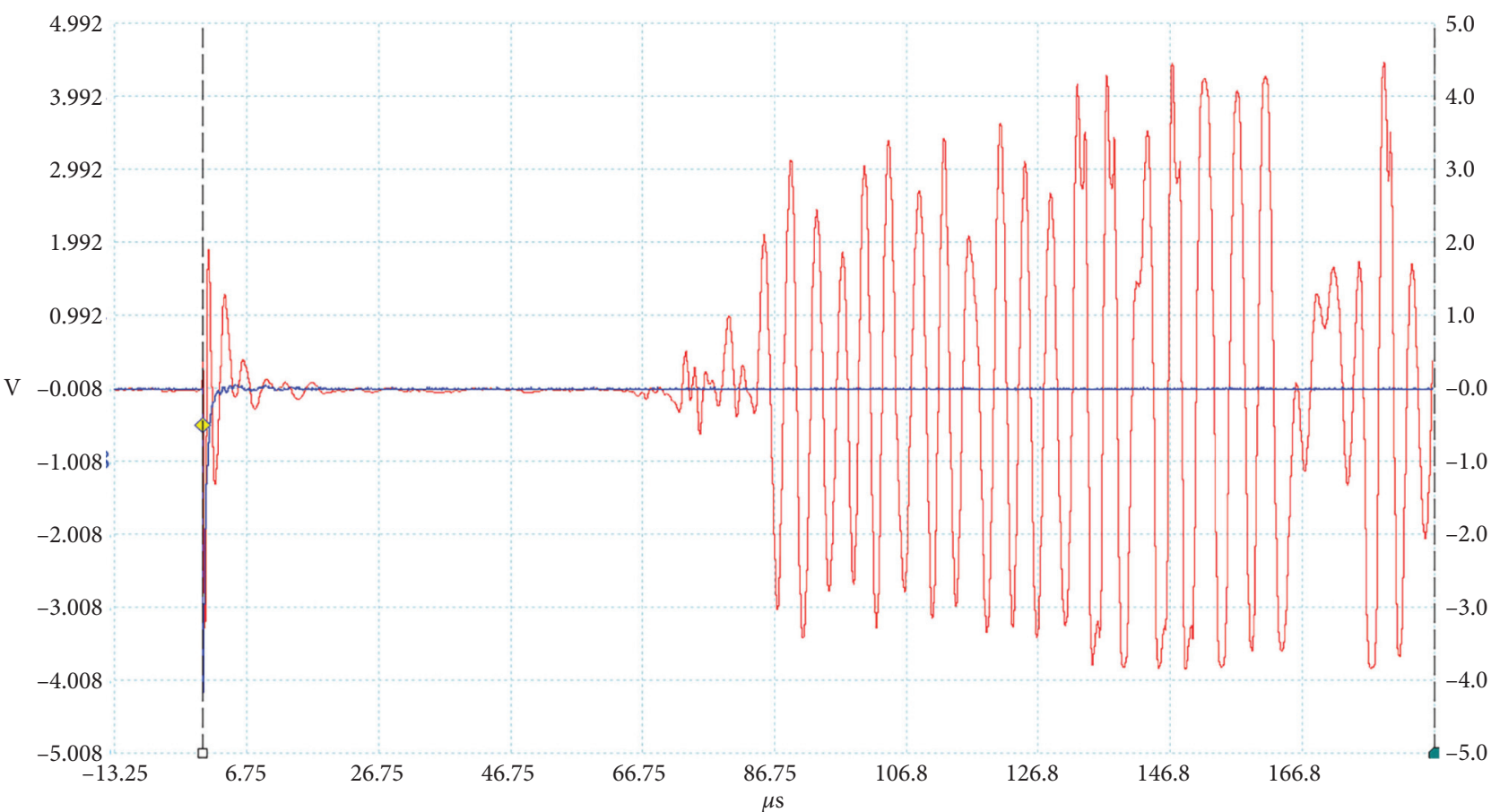

(a)

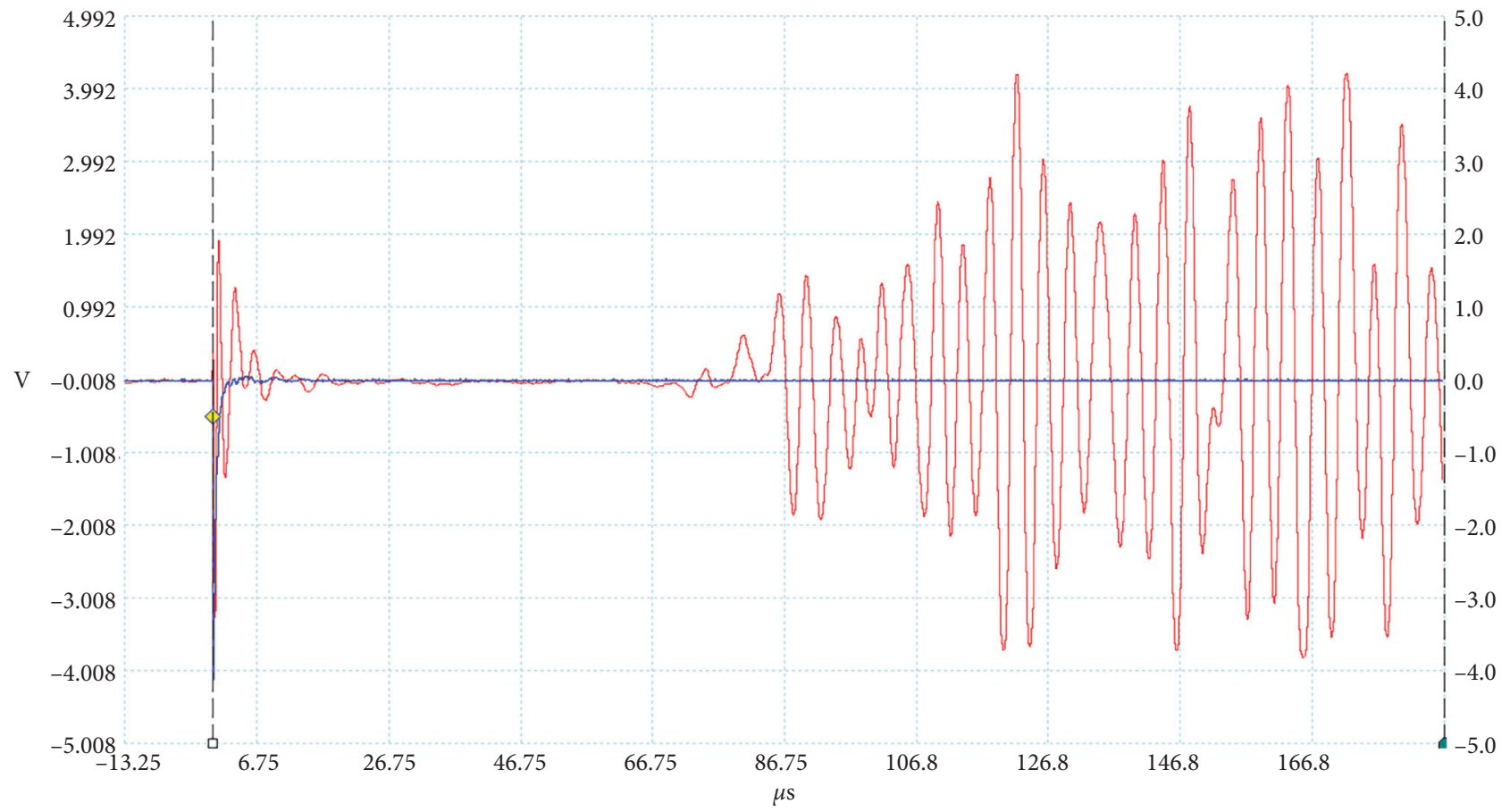

(b)

FIgURe 11: Continued. 


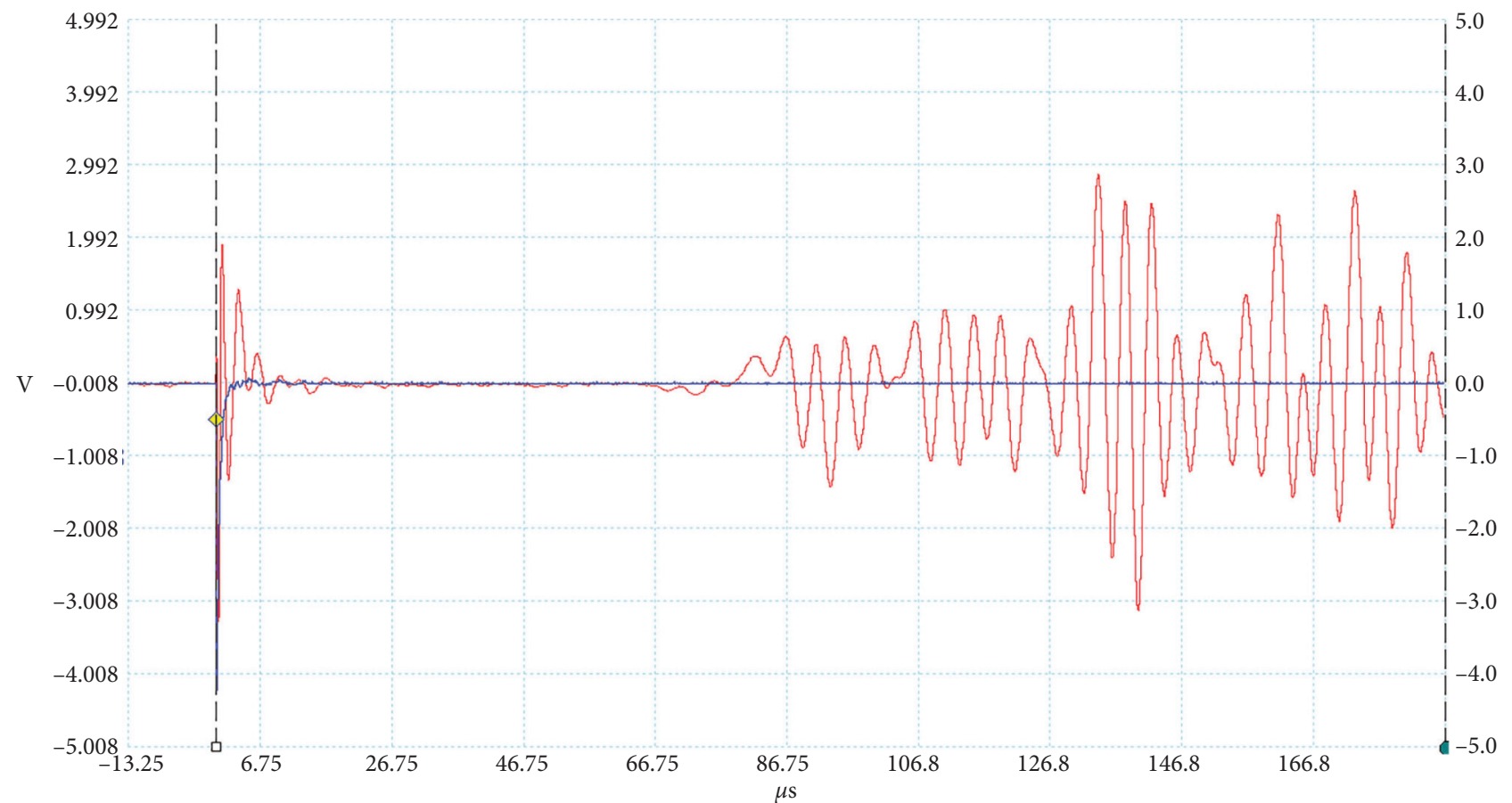

(c)

Figure 11: Waveforms recorded at different moments of unloading process. (a) $0.5 \mathrm{MPa} / \mathrm{min}$, (b) $1.0 \mathrm{MPa} / \mathrm{min}$, and (c) $2.0 \mathrm{MPa} / \mathrm{min}$.

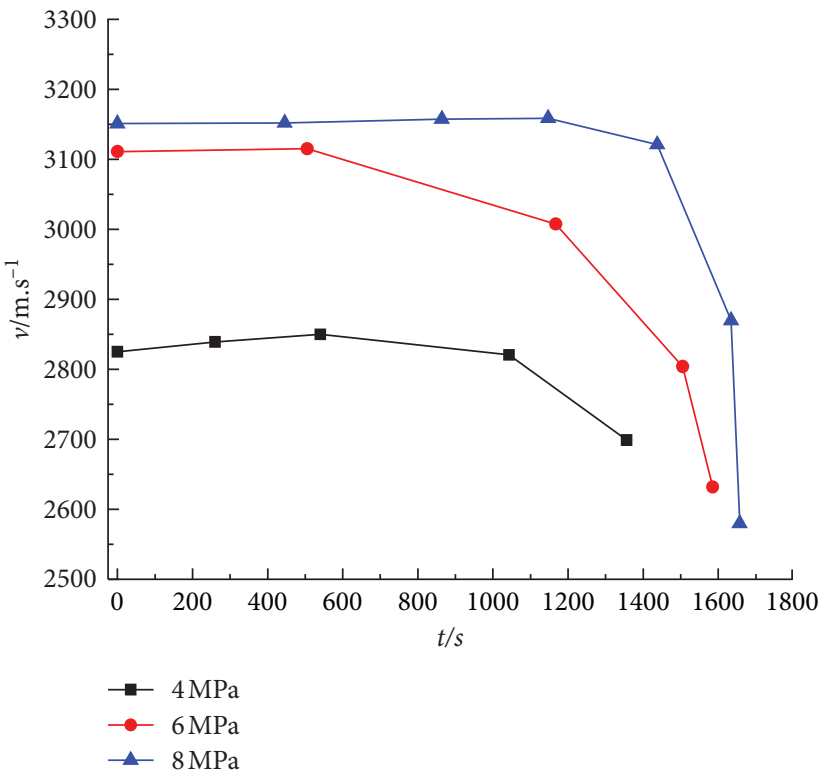

FIGURE 12: Variations of AW velocity under different initial confining pressures.

The variations of AW velocity and volumetric strain under different initial confining pressures during the unloading process are similar (shown in Figure 14). Before the unloading point, the axial pressure continuously increases until the deviator stress reaches predetermined value. During this short process, volumetric strain undergoes an increase stage due to change of axial strain. The rock sample

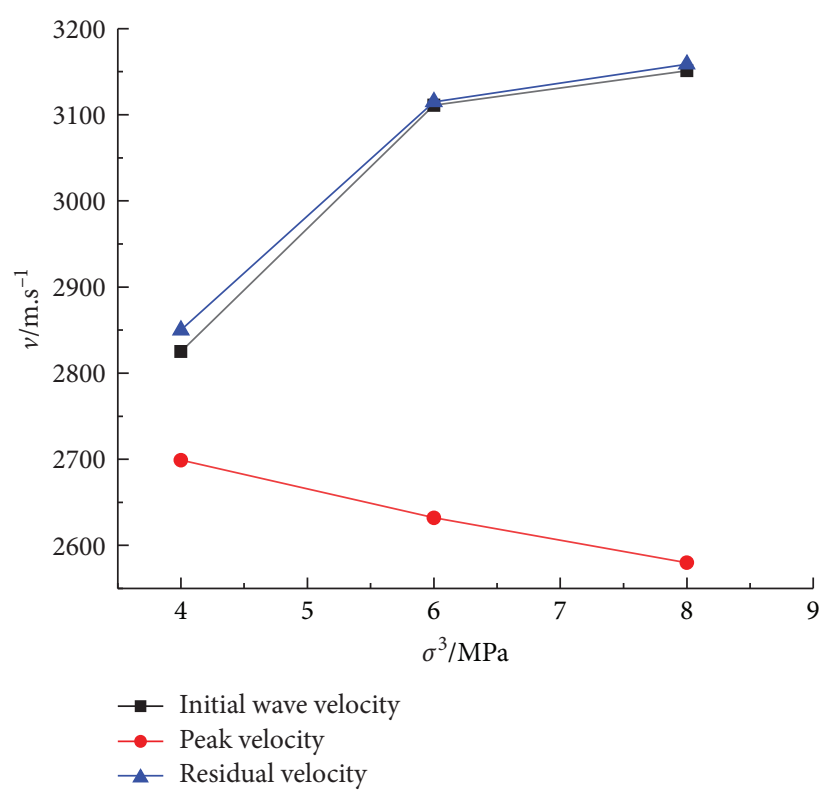

FIgURE 13: Relation curves of AW velocity and initial confining pressure.

is compressed by the deviator stress while the circumferential strain remains constant. Therefore, this process is called axial compaction phase, during which the axial compaction causes a slight increase of AW velocity. After the unloading point, the deviator stress remains constant while the confining pressure gradually decreases, and the rock sample gradually loses confining pressure. Under the force 


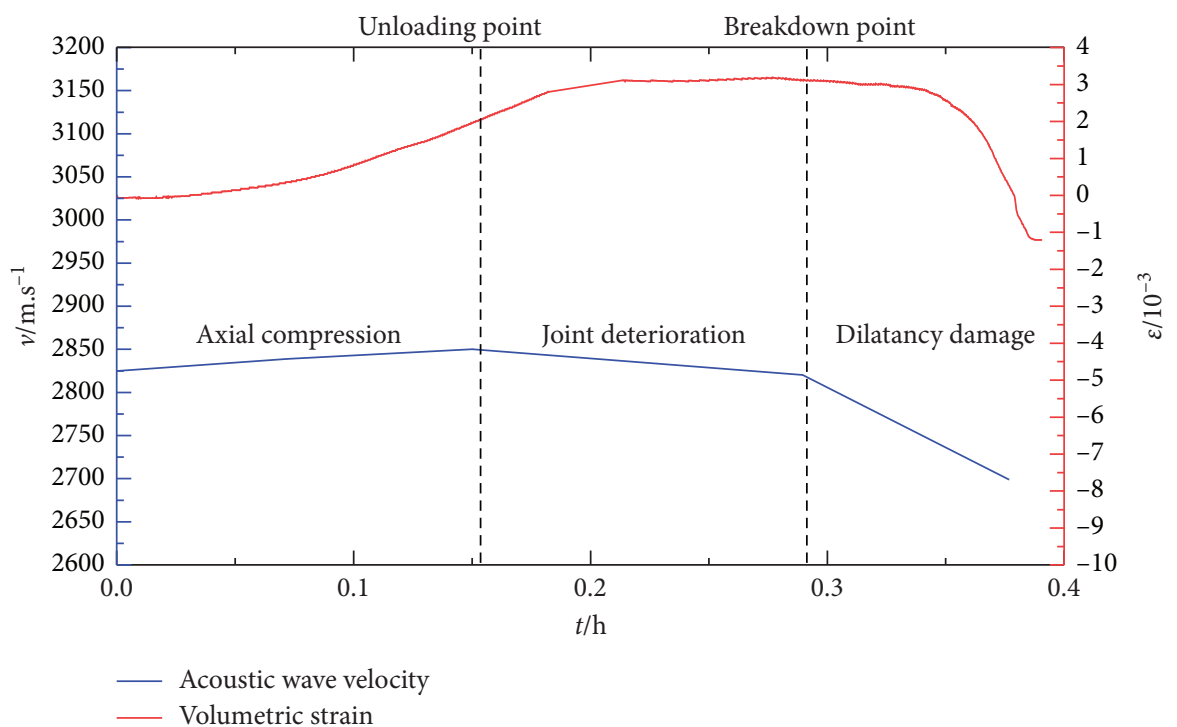

(a)

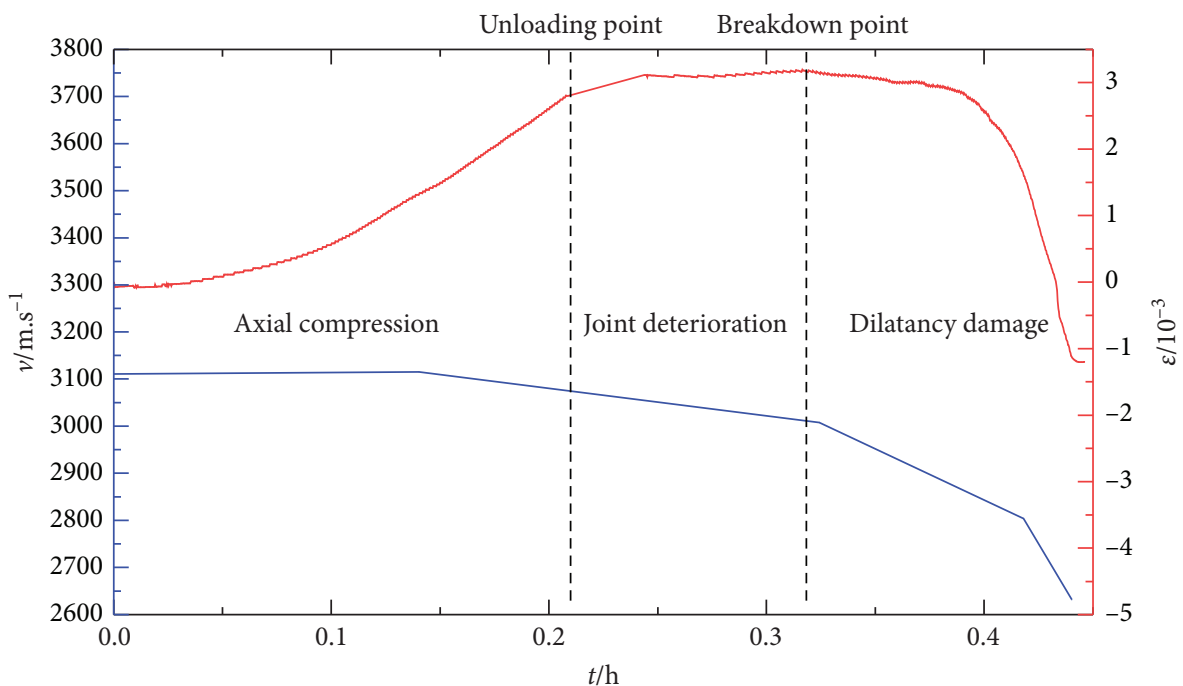

Acoustic wave velocity

Volumetric strain

(b)

Figure 14: Continued. 


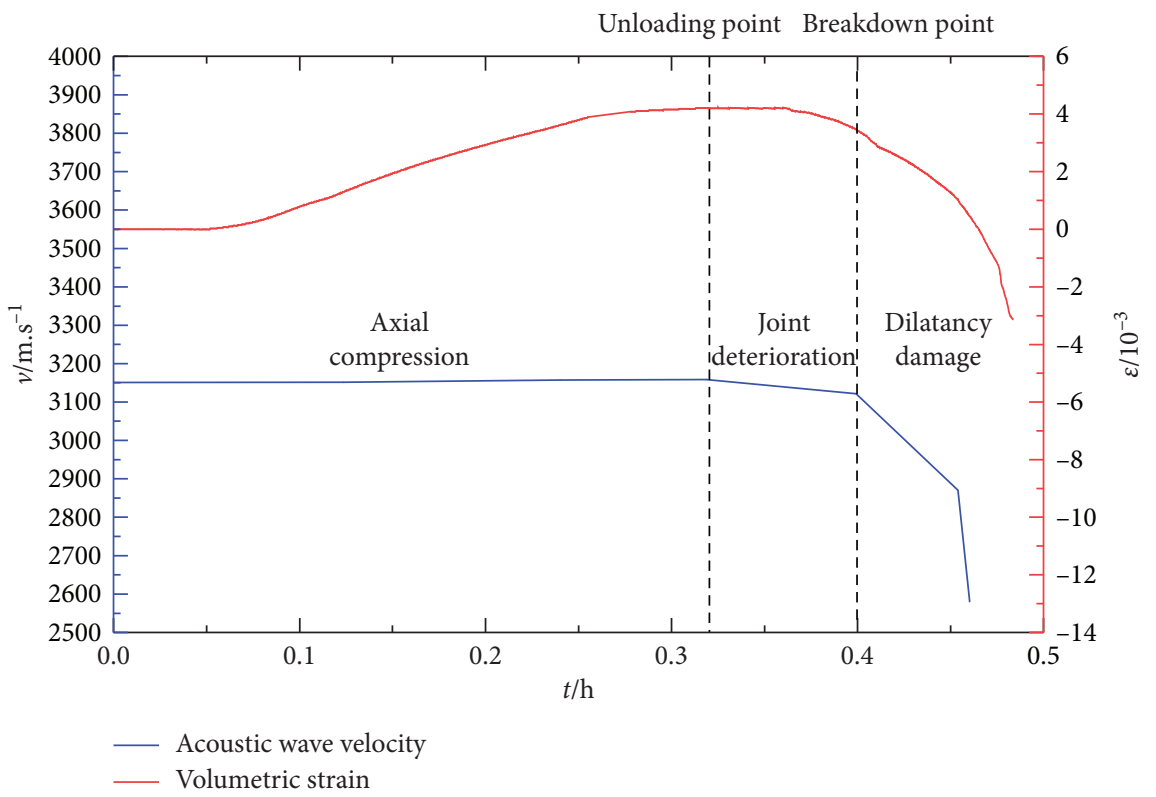

(c)

FIGURE 14: Variations of AW velocity and volumetric strain under different initial confining pressures. (a) $4 \mathrm{MPa}$, (b) $6 \mathrm{MPa}$, and (c) $8 \mathrm{MPa}$.

of deviator stress, joint planes gradually open and slip, and the circumferential strain increases, leading to the decrease of volumetric strain. Since the confining pressure remains above a certain amount, the rock sample will not be in failure. Therefore, this process is joint deterioration phase, during which $\mathrm{AW}$ velocity decreases slightly. When the confining pressure is discharged to a certain level, the joint planes cannot withstand the predetermined deviator stress, thus opening and sliding quickly. Meanwhile, the circumferential strain increases rapidly, accompanied by remarkable volumetric dilatancy, and the rock sample finally collapsed. Therefore, this process is failure phase, during which the AW velocity rapidly drops to a lower level.

A strong correlation between AW velocity and volumetric strain can be found in Figure 15. In the phase of constant confining pressure, AW velocity is positively related to volumetric strain, and volumetric strain in this phase is mainly controlled by the axial strain. The axial compaction of rock sample causes a slight increase of AW velocity, which corresponds to the phenomenon that AW velocity in columnar-jointed basalts of Baihetan dam foundation slightly increases during the pouring stage. In the phase of unloading confining pressure, AW velocity is negatively related to the volumetric strain that is controlled by both axial and circumferential strains. The addition and expansion of inner cracks caused by unloading could lead to the decrease of AW velocity.

\subsection{AW Velocity Characteristics at Different Unloading Rates.}

The AW velocity characteristics of CJRM-like material samples under initial confining pressure of $6.0 \mathrm{MPa}$ and different unloading rates $(0.5 \mathrm{MPa} / \mathrm{min}, 1.0 \mathrm{MPa} / \mathrm{min}$, and 2.0 MPa) are recorded and shown in Figure 16. Values of initial wave velocity, peak wave velocity, and failure wave

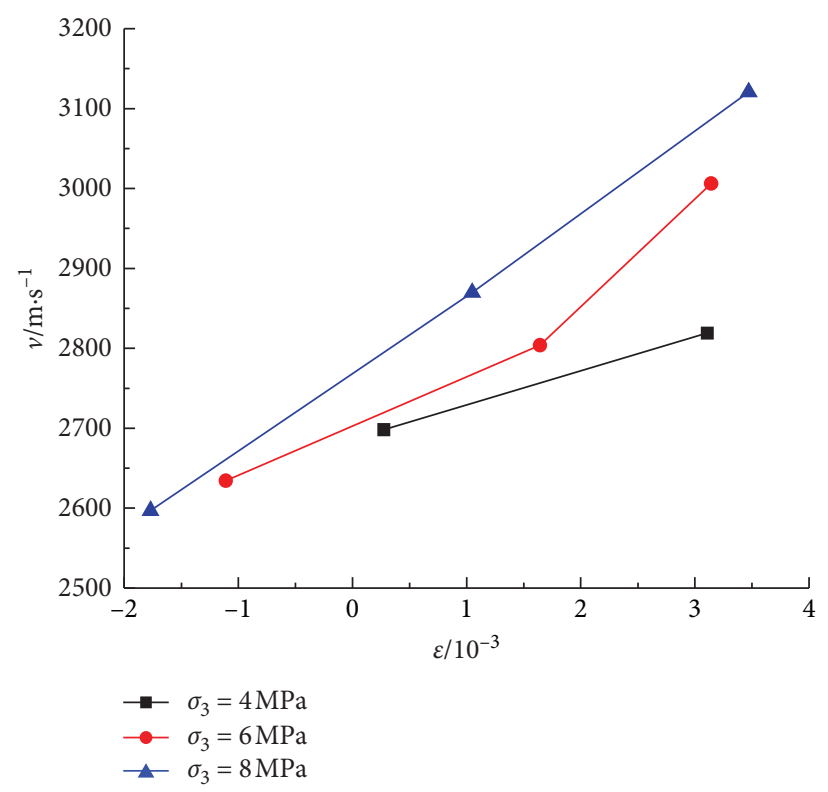

FIGURE 15: Relation of acoustic and volumetric strain under different initial confining pressures.

velocity at different unloading rates are different: at unloading rate of $0.5 \mathrm{MPa} / \mathrm{min}$, the initial wave velocity is $3111 \mathrm{~m} / \mathrm{s}$, the peak wave velocity is $3115 \mathrm{~m} / \mathrm{s}$, and the failure wave velocity is $2632 \mathrm{~m} / \mathrm{s}$; at unloading rate of $1.0 \mathrm{MPa} / \mathrm{min}$, the initial wave velocity is $3139 \mathrm{~m} / \mathrm{s}$, the peak wave velocity is $3160 \mathrm{~m} / \mathrm{s}$, and the failure wave velocity is $2222 \mathrm{~m} / \mathrm{s}$; at unloading rate of $2.0 \mathrm{MPa} / \mathrm{min}$, the initial wave velocity is $3096 \mathrm{~m} / \mathrm{s}$, the peak wave velocity is $3098 \mathrm{~m} / \mathrm{s}$, and the failure wave velocity is $2105 \mathrm{~m} / \mathrm{s}$.

The relationship curves between AW velocity and unloading rate of CJRM-like material samples with joint dip 


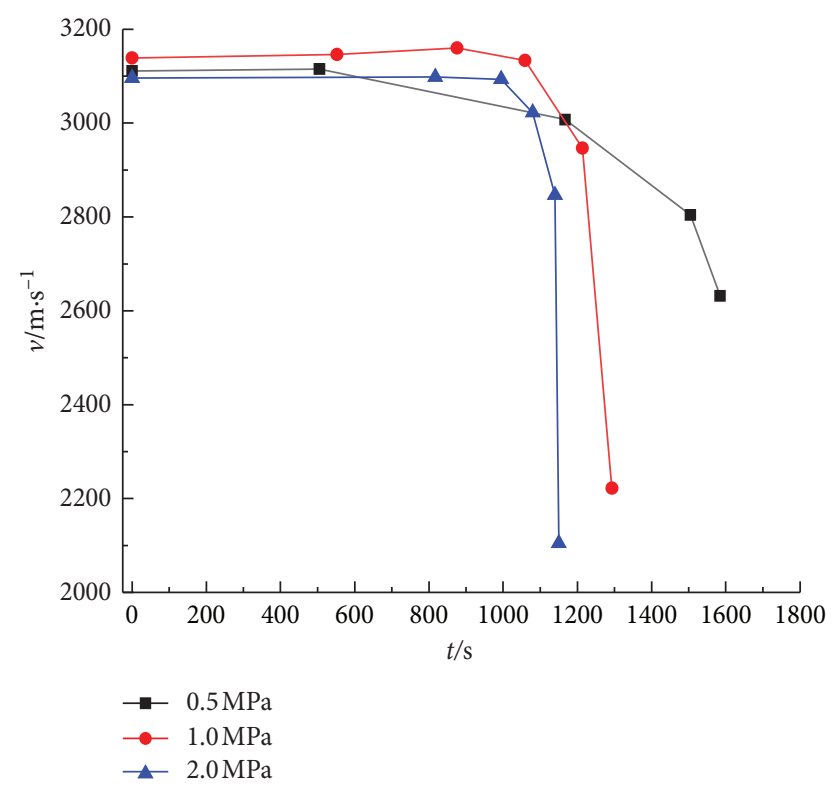

FIGURE 16: Variation of AW velocity at different unloading rates.

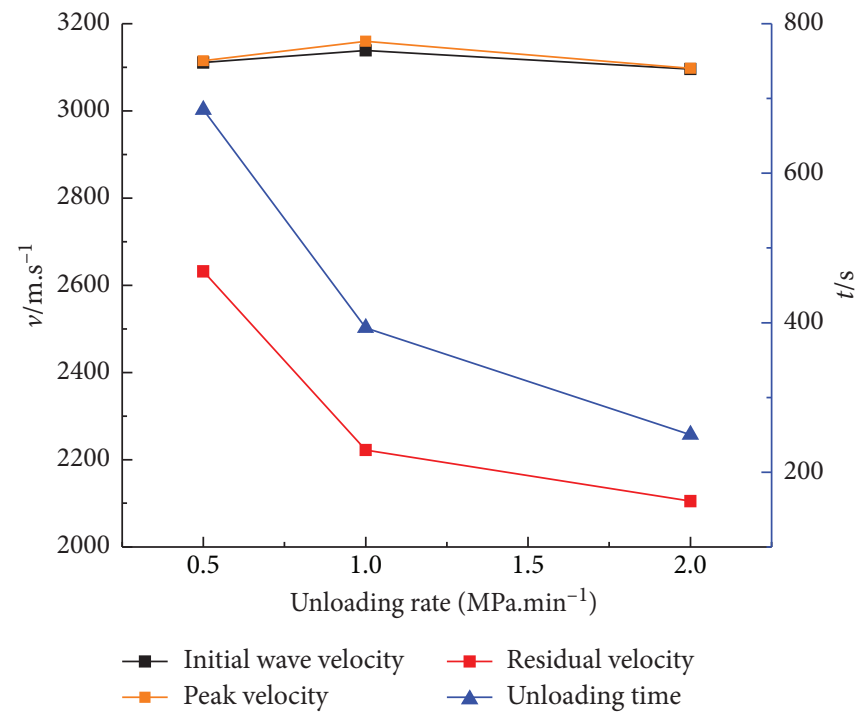

FIGURE 17: Relation curves of AW velocity and unloading rate.

of $75^{\circ}$ are shown in Figure 17. The time from unloading point to complete failure is also shown. The failure time values corresponding to the unloading rates of $0.5 \mathrm{MPa} / \mathrm{min}$, $1.0 \mathrm{MPa} / \mathrm{min}$, and $2.0 \mathrm{MPa} / \mathrm{min}$ are $685 \mathrm{~s}, 393 \mathrm{~s}$, and $250 \mathrm{~s}$, respectively. It can be concluded that the larger the unloading rate, the quicker and more intense the failure of the CJRM-like material samples.

\section{Conclusions}

By conducting a series of triaxial unloading tests with CJRMlike material samples, the stress-strain characteristics, strength and deformation patterns, and AW velocity characteristics during the unloading processes are studied. The main conclusions are as follows:

(1) The stress-strain curve of CJRM during unloading process can be divided into two phases. Phase I contains initial nonlinear compaction and linear elastic stages, which are similar to the triaxial compression test. The unloading process corresponds to phase II, during which both axial and circumferential deformations increase significantly and the dilatancy failure along the joint plane occurs.

(2) At relatively low unloading rates, the unloading section of the stress-strain curve will fluctuate 
significantly, and the failure process of the samples show an evolution of damage from partial to overall. When the unloading rate increases, the unloading section of the stress-strain curve becomes smoother and steeper, indicating that the increase of unloading rate may accelerate the failure process.

(3) Intense expansion along unloading direction occurs during triaxial unloading tests, and the failure modes can be summarized as two types: the sliding failure along the joint planes, and the combined failure of cement mortar columns and joint planes. With increase of the initial confining pressure and unloading rate, the failure of CJRM becomes more intense and the failure mode becomes more complicated.

(4) According to the AW velocity and strain, the unloading process of CJRM can be divided into three phases: the axial compaction, the joint deterioration, and the dilatancy failure. With increase of the initial confining pressure and unloading rate, the time of joint deterioration becomes shorter, the dilatancy failure becomes more severe, and the AW velocity decreases more rapidly.

(5) There is a strong correspondence between AW velocity and volumetric strain. During the unloading process, the AW velocity is negatively related to the volumetric strain that is controlled by both axial and circumferential strains. The addition and expansion of internal cracks caused by unloading lead to the decrease of AW velocity.

\section{Data Availability}

The data are available on request.

\section{Conflicts of Interest}

The authors declare that they have no conflicts of interest.

\section{Acknowledgments}

This research was supported by the National Key R\&D Program of China (no. 2018YFC0407004), the Fundamental Research Funds for the Central Universities (no. B200201059), and the Natural Science Foundation of China (Grant nos. 51709089, 51939004, and 11772116).

\section{References}

[1] Y. Wei, M. Xu, W. Wang, A. Shi, M. Tang, and Z. Ye, "Feasibility of columnar jointed basalt used for high-arch dam foundation," Journal of Rock Mechanics and Geotechnical Engineering, vol. 3, no. S1, pp. 461-468, 2011.

[2] Z.-G. Shan and S.-J. Di, "Loading-unloading test analysis of anisotropic columnar jointed basalts," Journal of Zhejiang University SCIENCE A, vol. 14, no. 8, pp. 603-614, 2013.

[3] A. Shi, M. Tang, and Q. Zhou, "Research of deformation characteristics of columnar jointed basalt at Baihetan hydropower station on Jinsha river," Chinese Journal of Rock Mechanics and Engineering, vol. 27, no. 10, pp. 2079-2086, 2008.
[4] W.-Y. Xu, W.-T. Zheng, and A.-C. Shi, "Classification and quality assessment of irregular columnar jointed basaltic rock mass for hydraulic engineering," Shuili Xuebao (Journal of Hydraulic Engineering), vol. 42, pp. 262-270, 2011.

[5] B.-R. Chen, Q.-P. Li, X.-T. Feng, Y.-X. Xiao, G.-L. Feng, and L.-X. Hu, "Microseismic monitoring of columnar jointed basalt fracture activity: a trial at the Baihetan hydropower station, China," Journal of Seismology, vol. 18, no. 4, pp. 773-793, 2014.

[6] Q.-X. Meng, H.-L. Wang, W.-Y. Xu, and Y.-L. Chen, "Numerical homogenization study on the effects of columnar jointed structure on the mechanical properties of rock mass," International Journal of Rock Mechanics and Mining Sciences, vol. 124, 2019.

[7] Q. Meng, H. Wang, M. He, J. Gu, J. Qi, and L. Yang, "Displacement prediction of water-induced landslides using a recurrent deep learning model," European Journal of Environmental and Civil Engineering, pp. 1-15, 2020.

[8] L. Yan, W. Xu, R. Wang, and Q. Meng, "Numerical simulation of the anisotropic properties of a columnar jointed rock mass under triaxial compression," Engineering Computations, vol. 35, no. 3, pp. 1788-1804, 2018.

[9] T. Li and L. Wang, "An experimental study on the deformation and failure features of a basalt under unloading condition," Chinese Journal of Rock Mechanics and Engineering, vol. 4, 1993.

[10] D.-J. Zhu, "Unloading effect and rapture zone distribution of columnar joints cavern," Journal of Zhejiang University (Engineering Science), vol. 44, no. 10, pp. 1967-1973, 2010.

[11] C. Zhu, M. He, M. Karakus, X. Cui, and Z. Tao, "Investigating toppling failure mechanism of anti-dip layered slope due to excavation by physical modelling," Rock Mechanics and Rock Engineering, vol. 53, no. 11, pp. 5029-5050, 2020.

[12] S. Qiu, X. Feng, C. Q. Zhang, H. Zhou, and F. Sun, "Experimental research on mechanical properties of deep-buried marble under different unloading rates of confining pressures," Chinese Journal of Rock Mechanics and Engineering, vol. 29, no. 9, pp. 1807-1817, 2010.

[13] D. Liu, Z. Gu, R. Liang et al., "Impacts of pore-throat system on fractal characterization of tight sandstones," Geofluids, vol. 2020, Article ID 4941501, 17 pages, 2020.

[14] B. Chen, S. Zhang, Y. Li, Z. Li, and H. Zhou, "Physical simulation study of crack propagation and instability information discrimination of rock-like materials with faults," Arabian Journal of Geosciences, vol. 13, 2020.

[15] J. Chen, J. Zhao, S. Zhang, Y. Zhang, F. Yang, and M. Li, “An experimental and analytical research on the evolution of mining cracks in deep floor rock mass," Pure and Applied Geophysics, vol. 177, pp. 5325-5348, 2020.

[16] S. Pei, X. Feng, J. Zhang et al., “Time-dependent relaxation characteristics of columnar jointed basalts in high-slope dam foundation during excavation," Rock and Soil Mechanics, vol. 39, no. 10, pp. 3743-3754, 2018.

[17] Q. Fan, Z. Wang, J. Xu, M. Zhou, Q. Jiang, and G. Li, “Study on deformation and control measures of columnar jointed basalt for baihetan super-high arch dam foundation," Rock Mechanics and Rock Engineering, vol. 51, no. 2, pp. 2569-2595, 2018.

[18] J. Wang, Y. Zhang, Z. Qin, S. Song, and P. Lin, "Analysis method of water inrush for tunnels with damaged waterresisting rock mass based on finite element method-smooth particle hydrodynamics coupling," Computers and Geotechnics, vol. 126, 2020. 
[19] Q. Meng, H. Wang, M. Cai, W. Xu, X. Zhuang, and T. Rabczuk, "Three-dimensional mesoscale computational modeling of soil-rock mixtures with concave particles," Engineering Geology, vol. 277, 2020.

[20] Q.-X. Meng, D. Lv, and Y. Liu, "Mesoscale computational modeling of concrete-like particle-reinforced composites with non-convex aggregates," Computers \& Structures, vol. 240, 2020.

[21] Q. X. Meng, H. L. Wang, W. Y. Xu, and M. Cai, "A numerical homogenization study of the elastic property of a soil-rock mixture using random mesostructure generation," Computers and Geotechnics, vol. 98, pp. 48-57, 2018.

[22] L. Yan, Q.-X. Meng, W.-Y. Xu et al., "A numerical method for analyzing the permeability of heterogeneous geomaterials based on digital image processing," Journal of Zhejiang University-SCIENCE A, vol. 18, no. 2, pp. 124-137, 2017.

[23] S. Wang, W. Xu, L. Yan, X.-T. Feng, W.-C. Xie, and H. Chen, "Experimental investigation and failure mechanism analysis for dacite under true triaxial unloading conditions," Engineering Geology, vol. 264, 2020.

[24] S. Wang, H. Wang, W. Xu, and W. Qian, "Investigation on mechanical behaviour of dacite under loading and unloading conditions," Géotechnique Letters, vol. 9, no. 2, pp. 130-135, 2019.

[25] C.-Y. Gao, J. Xu, P. He, and J.-F. Liu, "Study on mechanical properties of marble under loading and unloading conditions," Chinese Journal of Rock Mechanics and Engineering, vol. 24, pp. 456-460, 2005.

[26] R.-Q. Huang and D. Huang, "Experimental research on mechanical properties of granites under unloading condition," Chinese Journal of Rock Mechanics and Engineering, vol. 27, no. 11, pp. 2205-2213, 2008.

[27] S. Wang, W. Xu, C. Jia, and W. Wang, "Mechanical behavior of fine-grained sandstone in triaxial compression and elastoplastic modeling by return mapping algorithms," Bulletin of Engineering Geology and the Environment, vol. 77, no. 4, pp. 1689-1699, 2018. 